\title{
Eosinophilic vasculitis: A rare presentation of Whipple's disease
}

\author{
Waleed Al-hamoudi MD¹, Fadi Habbab MD², Carmine Nudo MD², Ayoub Nahal MD², ${ }^{2}$, Kenneth Flegel MD FRCPC ${ }^{2}$
}

\begin{abstract}
W Al-hamoudi, F Habbab, C Nudo, A Nahal, K Flegel. Eosinophilic vasculitis: A rare presentation of Whipple's disease. Can J Gastroenterol 2007;21(3):189-191.

Whipple's disease is a multisystem infectious disease caused by the bacterium Tropheryma whippelii. A case with an unusual presentation is reported. A 66-year-old man presented with a febrile vasculitic rash on his forearms. An extensive rheumatological, hematological and infectious workup gave negative results, apart from mild anemia and eosinophilia. An abdominal computed tomography revealed a retroperitoneal lymphadenopathy, and a skin biopsy revealed an eosinophilic vasculitis. This diverted the work toward ruling out a lymphoma or a vasculitic process. A lymph node biopsy was then performed and showed a diffuse neutrophilic inflammation with abundant foamy macrophages, fat necrosis and lipogranuloma formation. These findings were considered to be nonspecific and no further pathological investigation was carried out. After a course of corticosteroids, diarrhea and weight loss predominated and subsequently a diagnosis of Whipple's disease was confirmed on a small-bowel biopsy. Lymph node involvement was then confirmed on re-evaluation using the appropriate stains.
\end{abstract}

\section{Vascularite éosinophilique : Manifestation rare de la maladie de Whipple}

La maladie de Whipple est une maladie infectieuse plurisystémique causée par la bactérie Tropheryma whippelii. On fait ici état d'un cas inhabituel : un homme de 66 ans s'est présenté avec une éruption fébrile de type vascularite aux avant-bras. Des analyses complètes, rhumatologiques, hématologiques et bactériologiques ont donné des résultats négatifs, sauf une anémie et une éosinophilie légères. La tomographie abdominale a révélé une lymphadénopathie rétropéritonéale et la biopsie cutanée a révélé la présence d'une vascularite éosinophilique. Cela a permis de réorienter les démarches afin d'écarter un diagnostic de lymphome ou de vascularite. Une biopsie d'un ganglion lymphatique a ensuite été réalisée et a révélé une inflammation neutrophilique diffuse, accompagnée de macrophages spumeux abondants, de nécrose graisseuse et de formation de lipogranulomes. Ces observations ont été considérées non spécifiques et aucune autre analyse anatomopathologique n'a été effectuée. Après une corticothérapie, la diarrhée et la perte de poids ont prédominé et, par la suite, un diagnostic de maladie de Whipple a pu être confirmé grâce à une biopsie du grêle. L'atteinte des ganglions lymphatiques a ensuite été confirmée lors d'une réévaluation au moyen des colorants appropriés.

Key Words: Eosinophilic vasculitis; Lymphadenopathy; Whipple's disease

W Thipple's disease is a multiorgan disease that was first W described in 1907 (1). The causative organism was identified in 1992 and named Tropheryma whippelii (2). For unknown reasons this disease is more common in middle-aged men $(3,4)$.

Patients usually present with arthralgias, abdominal pain, fever or weight loss. Neurological and cardiovascular manifestations have also been described early on, making the diagnosis of this rare disease very challenging (3-5). Typically, digestive symptoms dominate the clinical picture as the disease progresses.

We report a case of Whipple's disease presenting a skin rash: an eosinophilic vasculitis with eosinophilia.

\section{CASE PRESENTATION}

A 66-year-old man presented to the emergency department with fever and a palpable skin rash on his forearms and hands (Figure 1). His system review and physical examination were both unremarkable.

An extensive rheumatological, hematological and infectious workup gave negative results, apart from mild anemia of $121 \mathrm{~g} / \mathrm{L}$ and an eosinophil count of $2.51 \times 10^{9} / \mathrm{L}$. Abdominal computed tomography scan revealed retroperitoneal lymphadenopathy. A skin biopsy was performed and was interpreted as necrotic eosinophilic vasculitis. To rule out lymphoma, a diagnostic laparoscopy with an abdominal lymph node biopsy was performed which revealed a diffuse neutrophilic inflammation with abundant foamy macrophages, fat necrosis and lipogranuloma formation. These findings were considered to be nonspecific, and no further pathological investigation was carried out.

Subsequently, the patient was treated with corticosteroids, and the fever and rash resolved. One month after discharge, he returned with severe diarrhea and dehydration. Repeat workup was again unremarkable with the exception that an abdominal computed tomography scan revealed persistent lymphadenopathy. He was discharged after mild improvement of the diarrhea after being put on an empirical trial of metronidazole. He was readmitted one month later with persistent diarrhea and a $4.5 \mathrm{~kg}$ weight loss. Repeat investigations revealed worsening anemia with a hemoglobin level of $109 \mathrm{~g} / \mathrm{L}$, a normal mean corpuscular volume, and an erythrocyte

${ }^{1}$ Department of Medicine, University of Western Ontario, London, Ontario; ${ }^{2}$ Department of Medicine; ${ }^{3}$ Department of Pathology,

McGill University, Montreal, Quebec

Correspondence: Dr Waleed Al-hamoudi, 339 Windermere Road, Room C4-216, University of Western Ontario, London, Ontario N6A 5A5.

Telephone 519-697-4811, fax 519-663-2967, e-mail walhamoudi@gmail.com

Received for publication June 21, 2006. Accepted June 22, 2006 


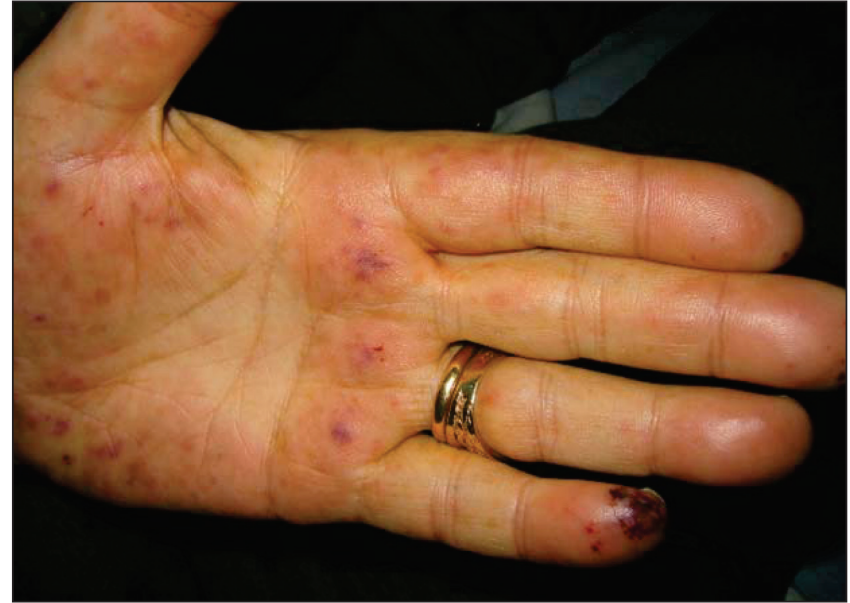

Figure 1) Palpable vasculitic rash on both hands

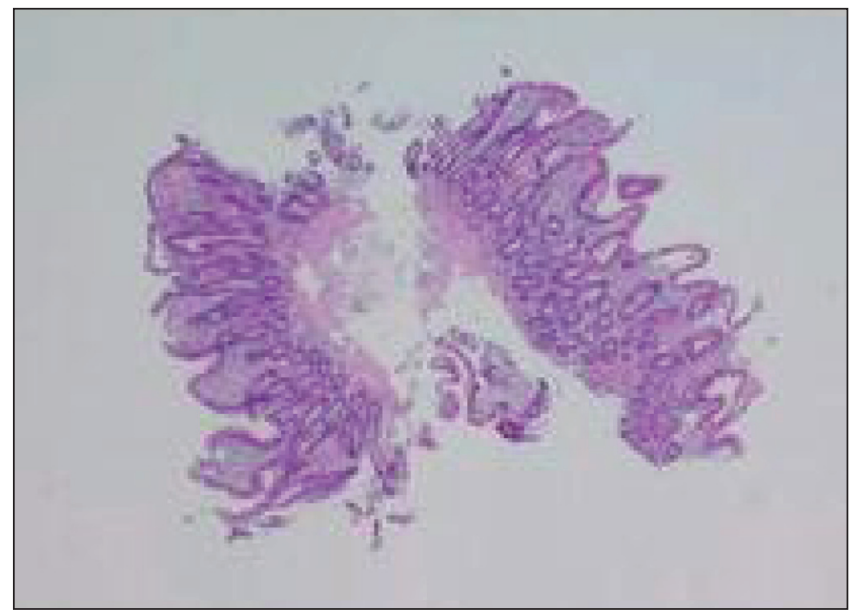

Figure 2) Duodenal biopsy showing effacement and blunting of the intestinal villi with histiocytic infiltration of the lamina propria, diagnostic of Whipple's disease. Hematoxylin and eosin stain, original magnification $\times 4$

sedimentation rate of $37 \mathrm{~mm} / \mathrm{h}$. His serum albumin level was $20 \mathrm{~g} / \mathrm{L}$ but his liver profile was otherwise normal. His serum tissue transglutaminase antibody level was normal. He underwent a gastroscopy, and duodenal biopsies were obtained that revealed subtotal effacement of the intestinal villi with blunting as well as diffuse infiltration of the lamina propria by foamy macrophages (Figure 2). This histology was consistent with Whipple's disease and the diagnosis was confirmed by periodic acid-Schiff (PAS) staining which coarsely dyed the intracytoplasmic granules. At this time, the pathology of the abdominal lymph node was reinvestigated and the diagnosis of Whipple's disease involving the lymph node was made (Figure 3). It was confirmed by the PAS-positive reaction of the infiltrating macrophages in a fashion similar to the intestinal biopsy (Figure 4).

The patient was treated with a two-week course of intravenous ceftriaxone and later, trimethoprim and sulfamethoxazole (one double-strength tablet taken twice a day) were administered, with a plan to continue the treatment

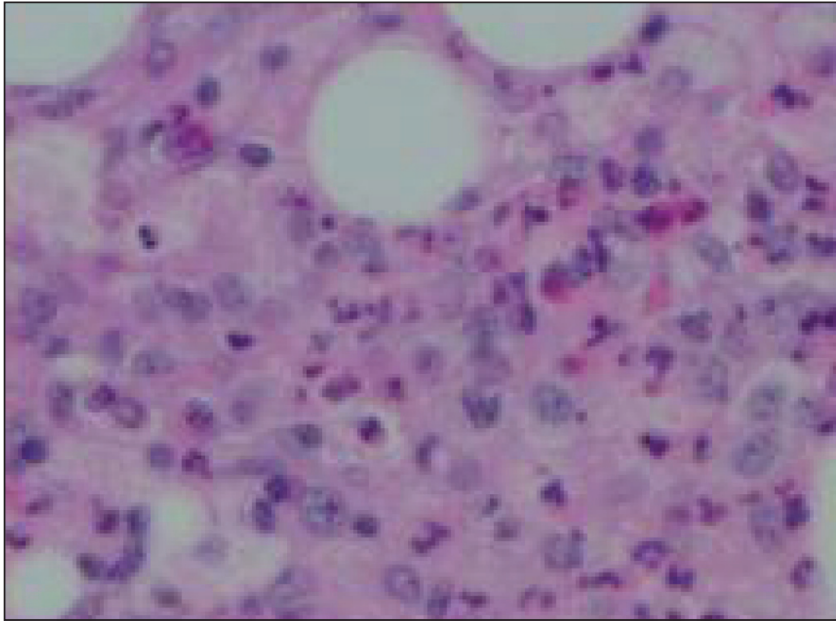

Figure 3) Intranodal infiltration of foamy macrophages, neutrophils, plasma cells and eosinophils (lymph node). Hematoxylin and eosin stain, original magnification $\times 40$

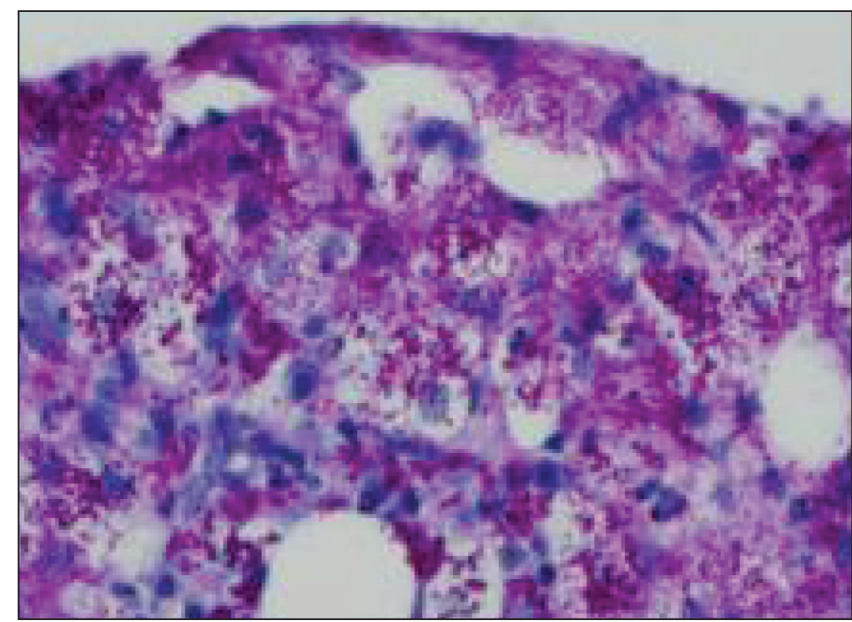

Figure 4) Positive, coarse periodic acid-Schiff particles present in the cytoplasm of macrophages representing the lysosomal location of the Tropheryma whippelii bacteria (lymph node). Original magnification $\times 40$

for one year. Within the first few weeks of treatment, his diarrhea resolved and he started gaining weight.

\section{DISCUSSION}

The typical clinical manifestations of Whipple's disease, namely diarrhea, weight loss and malabsorption, are present in the majority of patients at the time of diagnosis (3). However, these symptoms are usually preceded by a wide range of symptoms such as arthralgias and abdominal pain, and general systemic features such as fever and weight loss. Neurological and cardiovascular manifestations occur typically late in the course but have been described at the initial presentation in the absence of significant gastrointestinal complaints, making the diagnosis of this rare disease further challenging.

In the current case, the presentation was a vasculitic skin rash, fever and eosinophilia. Rarely has cutaneous manifestations been an early feature in this disease, and apart from five documented cases (6-10) in the literature of direct Whipple's involvement, cutaneous manifestations are generally 
nonspecific and related to malnutrition - hyperpigmentation, urticaria, erthythroderma and subcutaneous nodules. In the present case, cutaneous involvement with Whipple's disease was ruled out by re-examining the skin biopsy with PAS staining after Whipple's disease had been diagnosed.

We consider eosinophilic vasculitis to be a secondary manifestation of Whipple's disease. This is based on the temporal relationship between the appearance of the eosinophilic rash and the gastrointestinal symptoms, as well as the presence of eosinophils in the skin, small bowel and lymph nodes.

The diagnosis in the present case was delayed because of the unusual initial presentation leading to the workup directed toward a vasculitic process or a lymphoma. The correct diagnosis of Whipple's disease could have been reached earlier if it had been included in the differential diagnosis of abdominal lymphadenopathy and diarrhea.

Recently noninvasive testing using the polymerase chain reaction test for $T$ whippelii has been introduced, and probably explains the increased incidence of this disease (2). Similarly, the presence of foamy macrophages has been described in many organs in patients with Whipple's disease. Such extraintestinal involvement is not well characterized and can be missed if the appropriate stains are not used, as in the present case.

\section{REFERENCES}

1. Whipple GH. A hitherto undescribed disease characterized anatomically by defects of fat and fatty acids in the intestinal and mesenteric lymphatic tissues. John Hopkins Hosp Bull 1907; 18:382-91.

2. Relman DA, Schmidt TM, MacDermott RP, Falkow S. Identification of the uncultured bacillus of Whipple's disease. N Engl J Med 1992;327:293-301.

3. Durand DV, Lecomte C, Cathebras P, Rousset H, Godeau P. Whipple disease. Clinical review of 52 cases. The SNFMI Research Group on Whipple Disease. Societe Nationale Francaise de Medecine Interne. Medicine (Baltimore) 1997;76:170-84.

4. Dobbins WO III. Whipple's Disease. Springfield: Charles C Thomas, 1987.

5. Fleming JL, Wiesner RH, Shorter RG. Whipple's disease: Clinical, biochemical, and histopathologic features and
TABLE 1

Differential diagnoses of abdominal lymphadenopathy and recurrent diarrhea

\begin{tabular}{ll}
\hline - Lymphoma & - Whipple's disease \\
- Celiac disease & - Intestinal amyloidosis \\
- Crohn's disease & - Eosinophilic gastroenteropathy \\
- Infections & - Carcinoid tumour of small intestines \\
Tuberculosis & - Sarcoidosis \\
$\quad$ Clostridium difficile & - Intestinal lymphangiectasis \\
& \\
Histoplasma capsulatum & \\
\hline
\end{tabular}

\section{CONCLUSION}

Although rare, Whipple's disease should still be in the differential diagnosis of any unexplained digestive disease associated with intra-abdominal lymphadenopathy or systemic manifestations (Table 1). It is not uncommon that Whipple's disease has extraintestinal involvement (lymph nodes, liver, spleen, etc), so diagnostic suspicion should be heightened when an abundance of histiocytes accompanied by inflammatory infiltrates are seen. In such cases, a PAS stain or $T$ whippelii polymerase chain reaction test should be considered.

assessment of treatment in 29 patients. Mayo Clin Proc 1988;63:539-51.

6. Friedmann AC, Perera GK, Jayaprakasam A, Forgacs I, Salisbury JR, Creamer D. Whipple's disease presenting with symmetrical panniculitis. Br J Dermatol 2004;151:907-11.

7. Tarroch X, Vives P, Salas A, More J. Subcutaneous nodules in Whipple's disease. J Cutan Pathol 2001;28:368-70.

8. Good AE, Beals TF, Simmons JL, Ibrahim MA. A subcutaneous nodule with Whipple's disease: Key to early diagnosis? Arthritis Rheum 1980;23:856-9.

9. Kwee D, Fields JP, King LE Jr. Subcutaneous Whipple's disease. J Am Acad Dermatol 1987;16:188-90.

10. Balestrieri GP, Villanacci V, Battocchio S, Sleiman I, Facchetti F, Giustina G. Cutaneous involvement in Whipple's disease. Br J Dermatol 1996;135:666-8. 


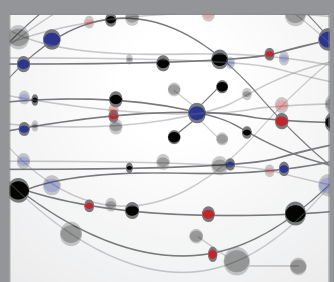

The Scientific World Journal
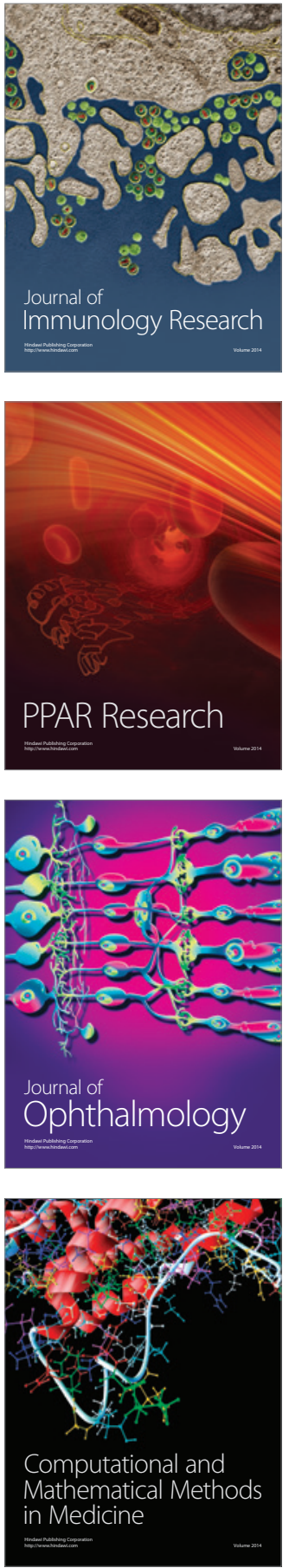

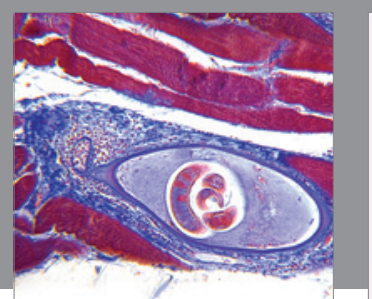

Gastroenterology Research and Practice

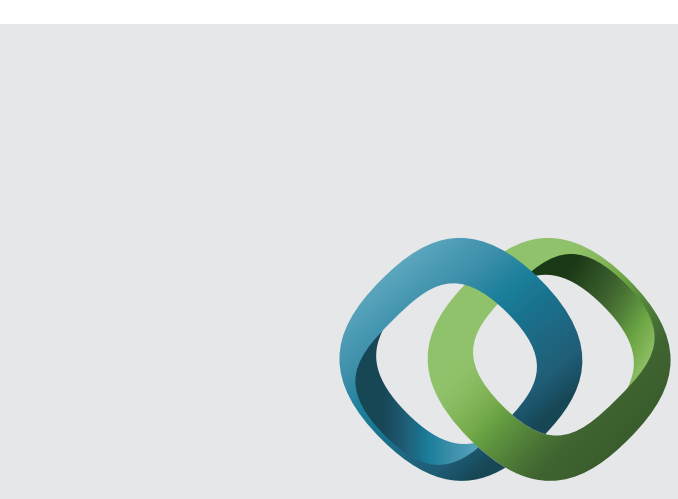

\section{Hindawi}

Submit your manuscripts at

http://www.hindawi.com
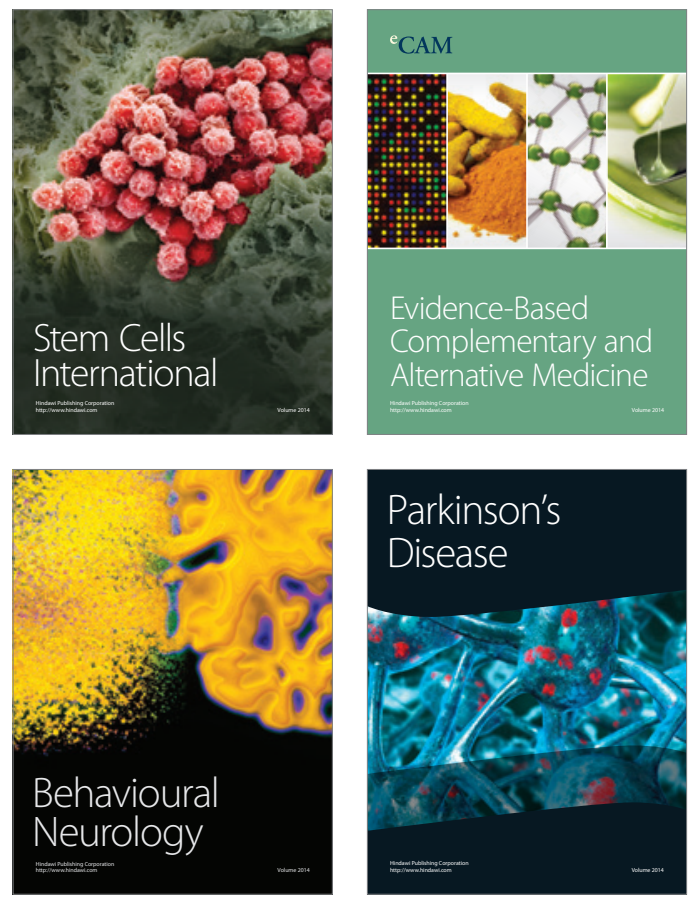
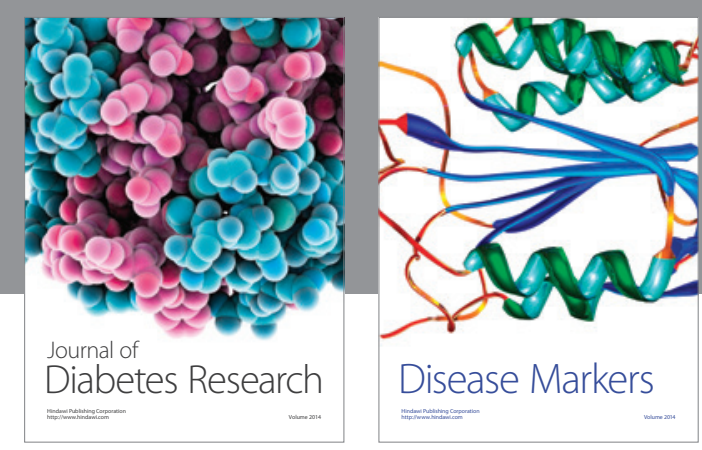

Disease Markers
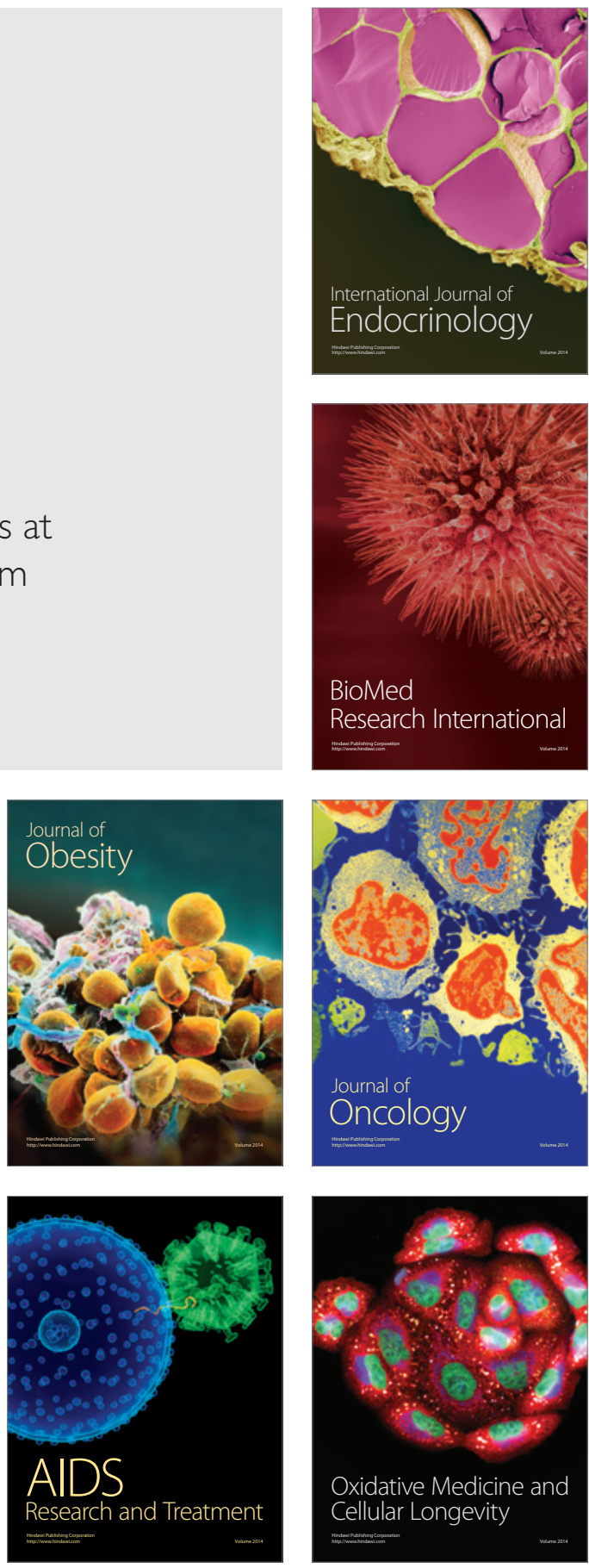